\title{
Effect of vitamin $C$ on sorbitol in the lens of guinea-pigs made diabetic with streptozotocin
}

\author{
BY C. J. BATES, T. D. COWEN AND P. H. EVANS \\ $M R C$ Dunn Nutritional Laboratory, Milton Road, Cambridge CB4 IXJ
}

(Received 5 November 1990-Accepted 5 July 1991)

\begin{abstract}
Marginally vitamin C-deficient guinea-pigs treated with the diabetogenic agent streptozotocin were compared with those liberally supplied with vitamin $\mathrm{C}$, for functional indices of vitamin $\mathrm{C}$ status, particularly in the eye lens. Weanling male Dunkin-Hartley guinea-pigs were fed on diets with $0.1 \mathrm{~g}$ vitamin C/kg (marginally deficient), or $5 \mathrm{~g} / \mathrm{kg}$ (liberally supplied), and some received intraperitoneal streptozotocin (two doses of $150 \mathrm{mg} / \mathrm{kg}$ body-weight). About half the streptozotocin-treated animals had high urinary glucose following an oral glucose dose; these animals also grew more slowly than the others. At $\mathbf{4}$ months after streptozotocin the animals were killed for measurement of tissue vitamin $C$, glucose and sorbitol. Streptozotocin moderately increased the concentration of glucose in plasma, lens and aqueous humour. Lens sorbitol levels increased only in the group exposed to streptozotocin plus marginal vitamin $C$. There was a significant $(P<0.02)$ positive correlation between urinary glucose and lens sorbitol levels overall. Liberal vitamin $C$ intake may thus counteract the effect of streptozotocin diabetes on lens sorbitol, suggesting a new function of vitamin C, possibly related to cataractogenesis and to the biochemical lesions associated with diabetes.
\end{abstract}

Guinea-pig lens: Vitamin C: Streptozotocin diabetes: Sorbitol

The role of ascorbic acid in the lens, and the effect of variations in vitamin $\mathrm{C}$ status in vivo on cataractogenesis, remain controversial and poorly defined. Several studies have implied that vitamin $\mathrm{C}$ has a deleterious pro-oxidant effect, and that it contributes directly to 'browning' reactions (Pirie, 1965; Fukui et al. 1973; Giblin et al. 1984; Bensch et al. 1985; Bron \& Brown, 1986; Riley et al. 1986; Russell et al. 1987; Trevithick et al. 1987; Ortwerth et al. 1988). Conversely, others have documented effects of the vitamin that imply protection by antioxidant or other mechanisms (Kosegarten \& Maher, 1978; Nishigori et al. 1985; Rosenbaum et al. 1985; Varma, 1985; Vinson et al. 1986; Williams \& Paterson, 1986; Taylor et al. 1987; Varma \& Richards, 1988; Koskela et al. 1989).

Vitamin C economy may become deranged in diabetic animals and humans (Cox et al. 1974; Ginter et al. 1978; Zebrowski \& Bhatnagar, 1979; Som et al. 1981; Yew, $1983 a, b$; Stankova et al. 1984; McLennan et al. 1988), and Vinson et al. (1989) found that ascorbic acid supplements reduced sorbitol concentrations in erythrocytes of diabetic human subjects.

The present study addressed the question whether vitamin $\mathrm{C}$ status can influence selected indices of streptozotocin (Stz) diabetes in guinea-pigs, and whether lens sorbitol levels are sensitive to vitamin $\mathrm{C}$ status in this model. Guinea-pigs were chosen because of their absolute requirement for dietary vitamin C. While less readily susceptible to Stz than rats, they have nevertheless been used successfully in a number of previous studies of diabetogenesis (Brosky \& Logothetopoulos, 1969; Wehner \& Majorek, 1975; Elliott \& Pogson, 1977; Klein et al. 1980; Schlosser et al. 1984, 1987). The clarification of possible 
influences of vitamin $\mathrm{C}$ in cataractogenesis in human diabetics is relevant to dietary advice or intervention for affected or high-risk groups.

\section{ANIMALS AND METHODS}

Weanling male Dunkin-Hartley guinea-pigs weighing 252 (SE 4) g were divided into four matched groups. Two groups received a purified diet with 'marginal' vitamin $\mathrm{C}$ content $(0.1 \mathrm{~g}(0.57 \mathrm{mmol}) / \mathrm{kg}$ diet $)$, and two received the same diet with a 'liberal' supply of vitamin $\mathrm{C}(5 \mathrm{~g}(28.4 \mathrm{mmol}) / \mathrm{kg}$ diet). One group on each diet was treated with Stz (see below); the other (control group) received a buffer ( $50 \mathrm{~mm}$-sodium citrate, $\mathrm{pH} 5$ ) injection.

Diets (Bates \& Cowen, 1988) comprised $(\mathrm{g} / \mathrm{kg})$ : maize starch 200, purified casein 300 , maize oil 74 , cellulose powder 150 , sucrose 103 , glucose 78 , potassium acetate 25 , magnesium oxide 5, choline chloride 2 , inositol 2, thiamine $16 \mathrm{mg}$, riboflavin $16 \mathrm{mg}$, pyridoxine $16 \mathrm{mg}$, calcium pantothenate $40 \mathrm{mg}$, nicotinamide $200 \mathrm{mg}$, pteroylglutamic acid $10 \mathrm{mg}$, biotin $1.2 \mathrm{mg}$, cyanocobalamin, $50 \mu \mathrm{g}$, retinyl acetate $2.3 \mathrm{mg}$, cholecalciferol $7.4 \mu \mathrm{g}$, $\alpha$-tocopherol $60 \mathrm{mg}$, menaphthone $10 \mathrm{mg}$ and Briggs salt mix (Greenfield et al. 1969) $60 \mathrm{~g}$. Ascorbic acid $(0.1 \mathrm{~g} / \mathrm{kg}$ diet $)$ was added for the animals on the marginal vitamin $\mathrm{C}$ diet; for those with a liberal supply of vitamin $\mathrm{C}, 5.0 \mathrm{~g} / \mathrm{kg}$ diet was added. Diets were stored at $4^{\circ}$ and made up at frequent intervals to avoid deterioration. A small amount of autoclaved hay was provided daily to ensure optimum bowel function. The animals were housed singly in suspended wire cages, with a $12 \mathrm{~h}$ light-dark cycle, and were given drinking water ad lib.

At $5 \mathrm{~d}$ and again at $17 \mathrm{~d}$ after starting the two dietary regimens, each animal destined to be in the ' + Stz' groups received an intraperitoneal dose of Stz (Sigma, Poole, Dorset), $150 \mathrm{mg}(0.57 \mathrm{mmol}) / \mathrm{kg}$ body-weight, dissolved in $50 \mathrm{~mm}$-citrate buffer, $\mathrm{pH} 5$, under diethyl ether anaesthesia. The control groups received an equivalent amount of $50 \mathrm{~mm}$-citrate buffer alone.

Body-weights were monitored daily. One animal in the group receiving marginal vitamin $C$ and Stz-treated lost weight rapidly and died, after a period of satisfactory growth for 4 months. Since it was not possible to obtain reliable measurements of the tissue levels of metabolites from this animal, it has been excluded from the data-set.

Glucose-handling was monitored at the following intervals during the study: $3,4,4.5,6$, $7 \cdot 5,11.5$ and 18 weeks from the start of the special diets. This was achieved by giving glucose dissolved in water, by oral gavage, at $2 \mathrm{~g}(0 \cdot 011 \mathrm{~mol}) / \mathrm{kg}$ body-weight to each animal, and then collecting urine in a metabolism cage for $3 \mathrm{~h}$. The glucose content of the urine was measured on a Roche Cobas centrifugal analyser with a reagent kit (glucose $\mathrm{HK}$ Unikit III (Roche Products Ltd., Welwyn Garden City, Herts)) which is based on conversion of glucose to glucose-6-phosphate, followed by its oxidation to gluconate-6phosphate with concomitant reduction of $\mathrm{NAD}^{+}$to $\mathrm{NADH}$. The creatinine content of urine was measured with a reagent kit (Roche no. 1421) based on the Jaffé picrate reaction.

At 18 weeks after starting the special diets, all the animals were killed and the following assays were performed on the tissue extracts: (a) vitamin $\mathrm{C}$ (reduced ascorbate) concentrations in adrenals, liver, lens and aqueous humour, as described previously (Bates \& Cowen, 1988): (b) plasma, lens and aqueous humour glucose concentrations, by the Unikit III method described previously on metaphosphoric acid $(40 \mathrm{~g} / 1)$ or $0.4 \mathrm{M}$-perchloric acid extracts; $(c)$ lens and liver sorbitol concentrations by a procedure linked to sorbitol dehydrogenase (EC 1.1.1.14; cat. no. S3764, Sigma), as described by Bergmeyer (1974) and adapted to the Roche Cobas centrifugal analyser; $(d)$ exopeptidase and endopeptidase activities in saline extracts of lenses as described by Blondin et al. (1986), adapted to the centrifugal analyser; (e) ATP concentrations in $0.03 \mathrm{M}$-trichloroacetic acid extracts of lenses, by a chemiluminescence assay based on the luciferin-luciferase $(E C 1.14,14.3)$ 
reaction (LKB kit, cat. no. 1243-107; LKB-Produkter AB, Broma, Sweden); and ( $f$ ) acidsoluble thiol levels in metaphosphoric acid $(40 \mathrm{~g} / 1)$ extracts of lens and aqueous humour samples, by the dithiobis-(2-nitro-benzoic) acid reaction (Bates \& Cowen, 1988).

\section{Statistical treatment}

Comparisons between groups were performed by Student's $t$ test or by two-way ANOVA tests, as appropriate. Correlations between variables were tested by linear regression after logarithmic transformation, in order to correct for any non-normal distributions and nonlinear relationships. Not significant (NS) implies $P>0 \cdot 10$.

\section{RESULTS}

\section{Growth and urinary glucose following test-dosing}

Body-weight curves are shown in Fig. 1. Clearly the Stz-treated animals grew more slowly than the controls, and this was shown to be significant (ANOVA, $P<0.001$ ) at weeks 7 , 14 and 18 , i.e. throughout most of the study period. The dietary level of vitamin $\mathrm{C}$ had no significant effect on growth in this experiment.

The glucose assay was shown to be free from both positive and negative interference by vitamin $C$ concentrations up to $30 \mathrm{~mm}$ in the extracts, which was much greater than the concentrations observed (see Table 1).

When the change in body-weight over the 18-week study period was plotted $v$. median glucose:creatinine ratios in urine for individual animals averaged over the whole study (Fig. 2), it became clear that high glucose excretion was generally associated with poor growth. Only half the Stz-treated animals had raised mean glucose:creatinine ratios above $9 \mathrm{~mol} / \mathrm{mol}$.

Fig. 3 shows the time-course of median glucose:creatinine ratios following the oral glucose load. The ratios were raised in both the Stz-treated groups compared with controls throughout the study $(P<0.01)$, and the highest ratios were obtained in the early part of the study period. There was no significant vitamin C effect (ANOVA) at any of the timepoints, although a trend towards a more rapid decline in the urinary ratio at the higher vitamin $\mathrm{C}$ intake group was apparent.

\section{Ascorbic acid levels in tissue extracts}

Table 1 shows the concentrations of reduced ascorbic acid in four tissues of the four groups of animals. Clearly there was a highly significant effect of dietary vitamin $\mathrm{C}$, but no significant effect of Stz, on these ascorbic acid levels. As noted previously (Bates \& Cowen, 1988), the effects of the different dietary vitamin $C$ levels were far more dramatic in adrenals, liver and aqueous humour than in lenses, but the latter nevertheless exhibited highly significant vitamin $\mathrm{C}$-related differences.

\section{Glucose and sorbitol levels in lens, glucose in plasma and aqueous humour and sorbitol in liver}

Table 2 shows the influence of Stz and dietary vitamin $\mathrm{C}$ on tissue sugar levels. Clearly Stz treatment raised lens $(P<0.005)$, aqueous humour $(P<0.05)$, and plasma $(P<0.05)$ glucose levels significantly, but vitamin $C$ intake had no significant influence on this variable (ANOVA). Even after elimination of Stz non-responders from the Stz groups, there was still no evidence that the higher vitamin $C$ intake had reduced the accumulation of glucose at any of the three sites (plasma, aqueous humour, lens) examined.

Lens sorbitol levels were significantly $(P<0.05)$ raised in the + Stz marginal-vitamin $C$ group ( $t$ test) but were indistinguishable from control levels in the + Stz liberal-vitamin $C$ 


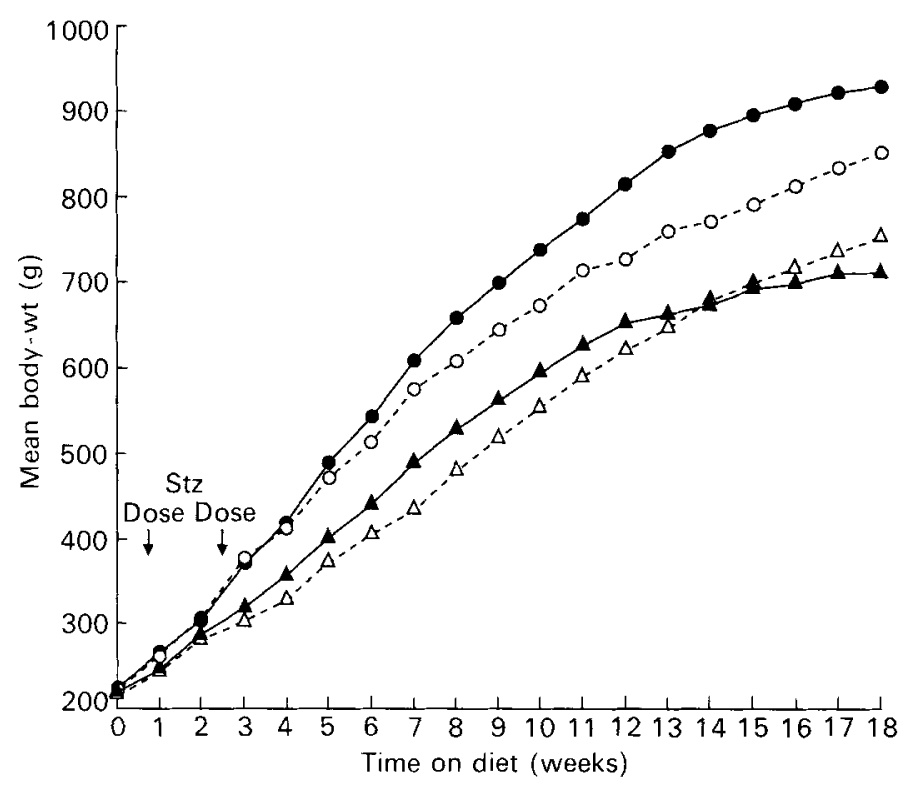

Fig. 1. Body-weights of guinea-pigs as a function of time-interval after initiating diets containing high $(5 \mathrm{~g} / \mathrm{kg})$ or low $(0.1 \mathrm{~g} / \mathrm{kg})$ vitamin $C$ levels with or without streptozotocin $(\mathrm{Stz})$ treatment. (O-- $\mathrm{O})$, Without Stz, low vitamin $\mathrm{C}(n 9$; SEM at week $18,32.4 \mathrm{~g}) ;(\bigcirc-O)$, without Stz, high vitamin $\mathrm{C}(n 9 ;$ SEM at week 18,349$) ;(\triangle--\triangle)$, with Stz, low vitamin C ( $n 8$; SEM at week $18,40.0)$; $(\mathbf{A}-\mathbf{A}$ ), with Stz, high vitamin $\mathrm{C}$ ( $n$ 9; sEM at week 18 , 45.9). A typical SEM at the start of the experiment was $48 \mathrm{~g}$. The statistical significance of the effects of Stz, vitamin $C$ and their interaction by two-way ANOVA at weeks 7,14 and 18 gave: Stz effect, $t 4.00-4 \cdot 25, P<0.001$; vitamin $\mathrm{C}$ effect, $t 0 \cdot 7-1 \cdot 5$, not significant; interaction term, $t 0 \cdot 4-1 \cdot 5$, not significant. For details of diets, treatments and procedures, see pp. 446-447.

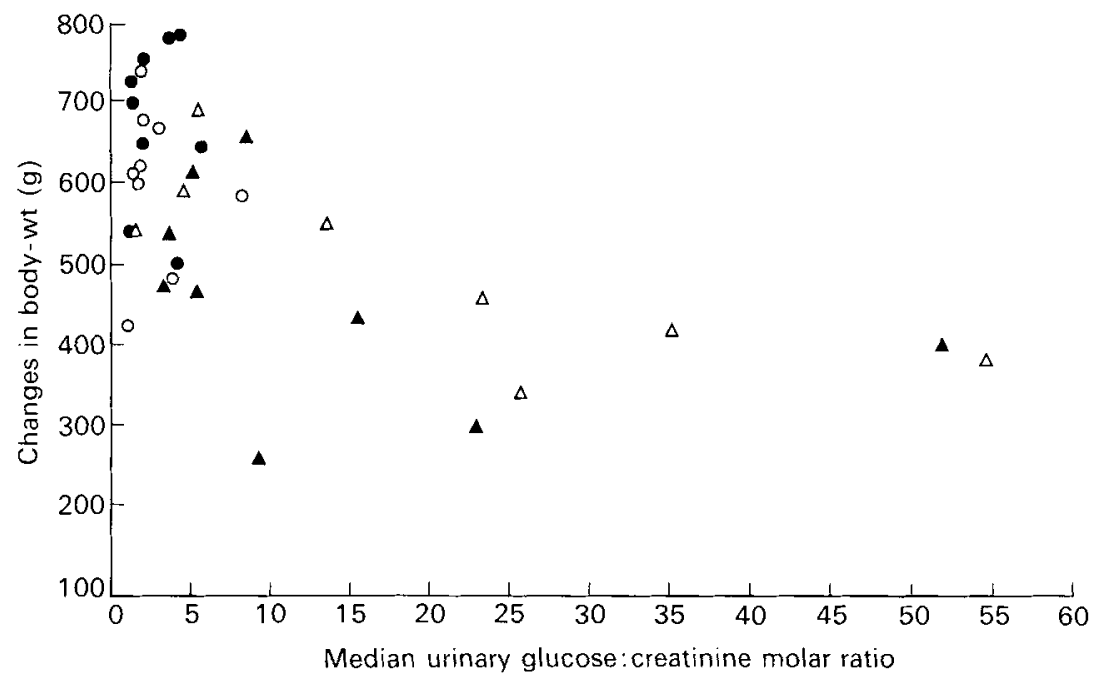

Fig. 2. Changes in body weight during the 18-week study period v. median urinary:creatinine molar ratios for each guinea-pig given diets containing high $(5 \mathrm{~g} / \mathrm{kg})$ or low $(0 \cdot 1 \mathrm{~g} / \mathrm{kg})$ vitamin $C$ levels with or without streptozotocin (Stz) treatment. (O), Without Stz, low vitamin $C(n 9) ;(\bigcirc)$, without $S t z$, high vitamin $C(n 9) ;(\triangle)$, with Stz, low vitamin $\mathrm{C}(n 8) ;(\boldsymbol{A})$, with Stz, high vitamin $\mathrm{C}(n 9)$. After logarithmic transformation of the displayed values: $r 0.61,34 \mathrm{df}, P<0.001$. For details of diets, treatments and procedures, see pp. 446447 . 


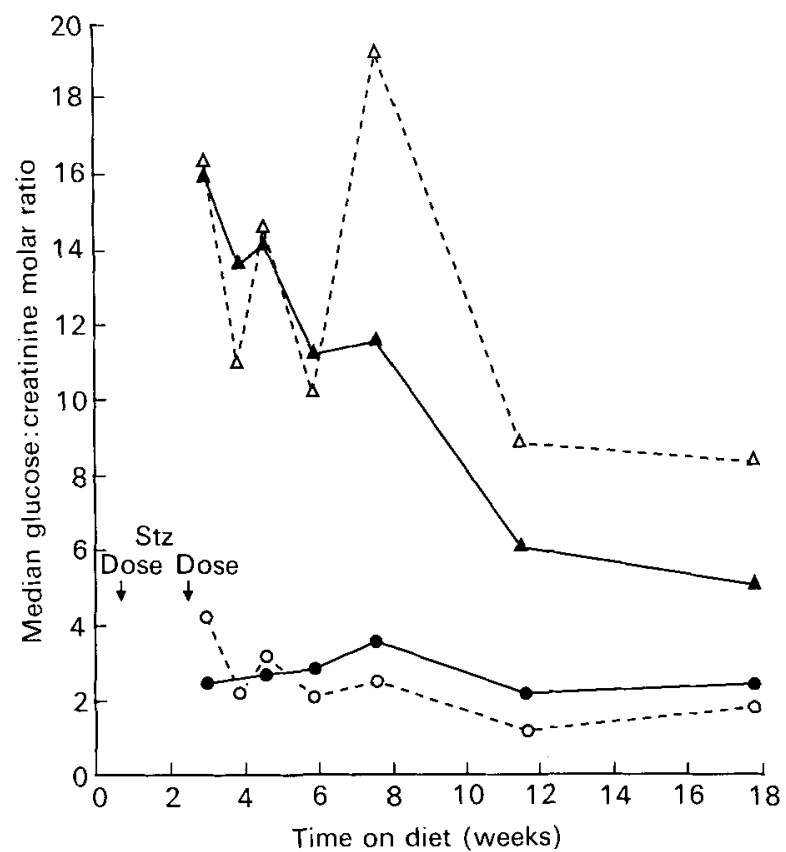

Fig. 3. Median urinary glucose:creatinine molar ratios after test-dosing at seven time-points spanning the study in guinea-pigs given diets containing high $(5 \mathrm{~g} / \mathrm{kg})$ or low $(0.1 \mathrm{~g} / \mathrm{kg})$ vitamin $\mathrm{C}$ levels with or without

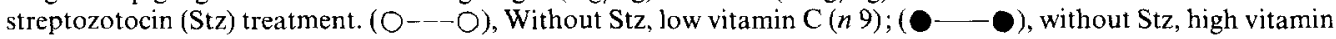
$\mathrm{C}(n 9) ;\left(\triangle^{---\triangle}\right)$, with Stz, low vitamin C $(n 8) ;(\mathbf{A}-\mathbf{\Delta})$, with Stz, high vitamin $\mathrm{C}(n 9)$. The statistical significance of the effects of Stz, vitamin $\mathrm{C}$ and their interaction by two-way ANOVA at weeks 4,6 and 18 gave: Stz effect, $t 2 \cdot 95-4 \cdot 10, P<0 \cdot 01$; vitamin $C$ effect, $t 0 \cdot 06-0 \cdot 40$, not significant; interaction term, $t 0 \cdot 14-0 \cdot 60$, not significant. For details of diets, treatments and procedures, see pp. 446-447.

group. There were significant effects of vitamin C, Stz, and the interaction term by two-way ANOVA, the interaction term being the most highly significant. When lens sorbitol levels v. urinary glucose:creatinine ratios were plotted (Fig. 4), it was clear that high urinary glucose was generally associated with high lens sorbitol levels $(r+0.40, P<0.02$ for $\log$ transformed data). For liver sorbitol levels (Table 2) there was a paradoxical reduction in the $+\mathrm{Stz}$ groups, but no significant vitamin $\mathrm{C}$ effect (ANOVA), and no significant correlation with urinary glucose:creatinine $(r-0 \cdot 24$, NS).

\section{ATP levels in lenses}

Lens ATP levels were positively correlated with urinary glucose:creatinine ratio $(r+0.52$, $P<0.001$ for log-transformed values); there was a borderline significant effect of Stz by ANOVA $(t 1 \cdot 89, P<0 \cdot 1)$, but no significant effect of vitamin C (Table 2 ).

\section{Peptidase levels in lenses; thiol levels in lenses and aqueous humour}

Table 3 shows that there were no significant effects of either Stz or vitamin C intake on the exopeptidase or endopeptidase activities in the lenses. Likewise, acid-soluble thiol levels in the lenses and aqueous humour samples were unaffected by the two treatments.

\section{DISCUSSION}

The present study, unlike those of Zebrowski \& Bhatnagar (1979), Som et al. (1981) and Yew $(1983 a, b)$ on rats and of Schlosser et al. (1987) on guinea-pigs, did not encounter any effect of Stz diabetes on tissue ascorbic acid levels in the guinea-pigs. Peptidase levels were 


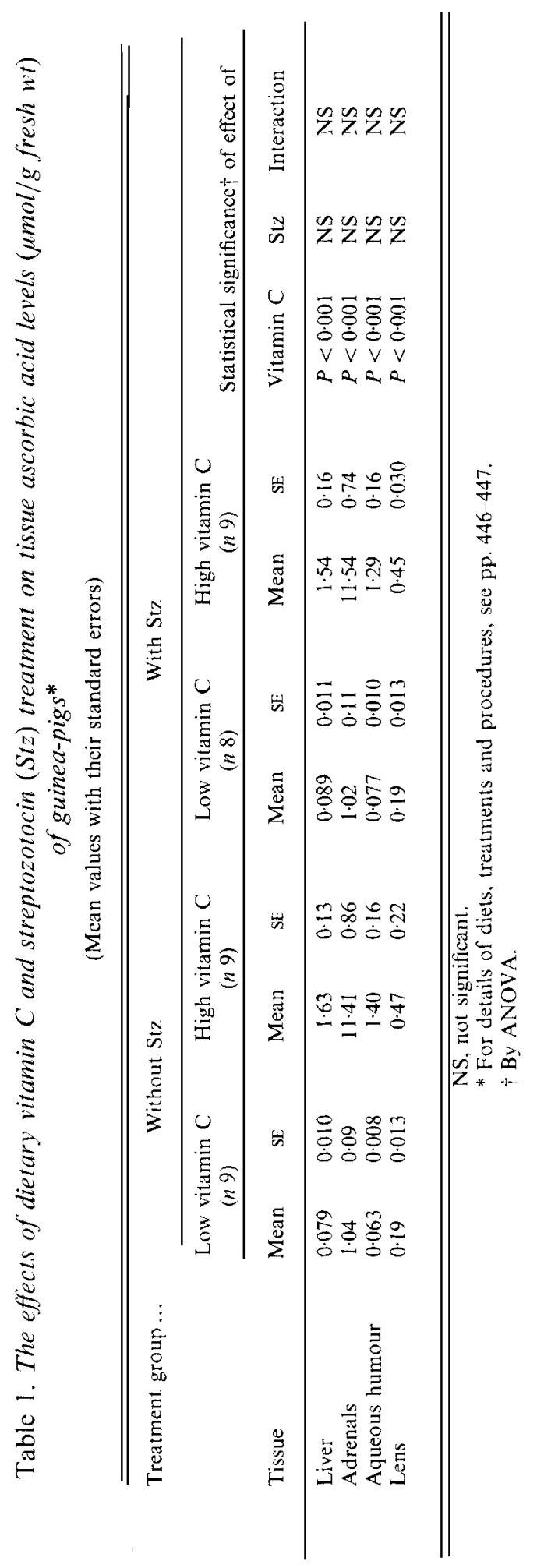


VITAMIN C, DIABETES AND SORBITOL

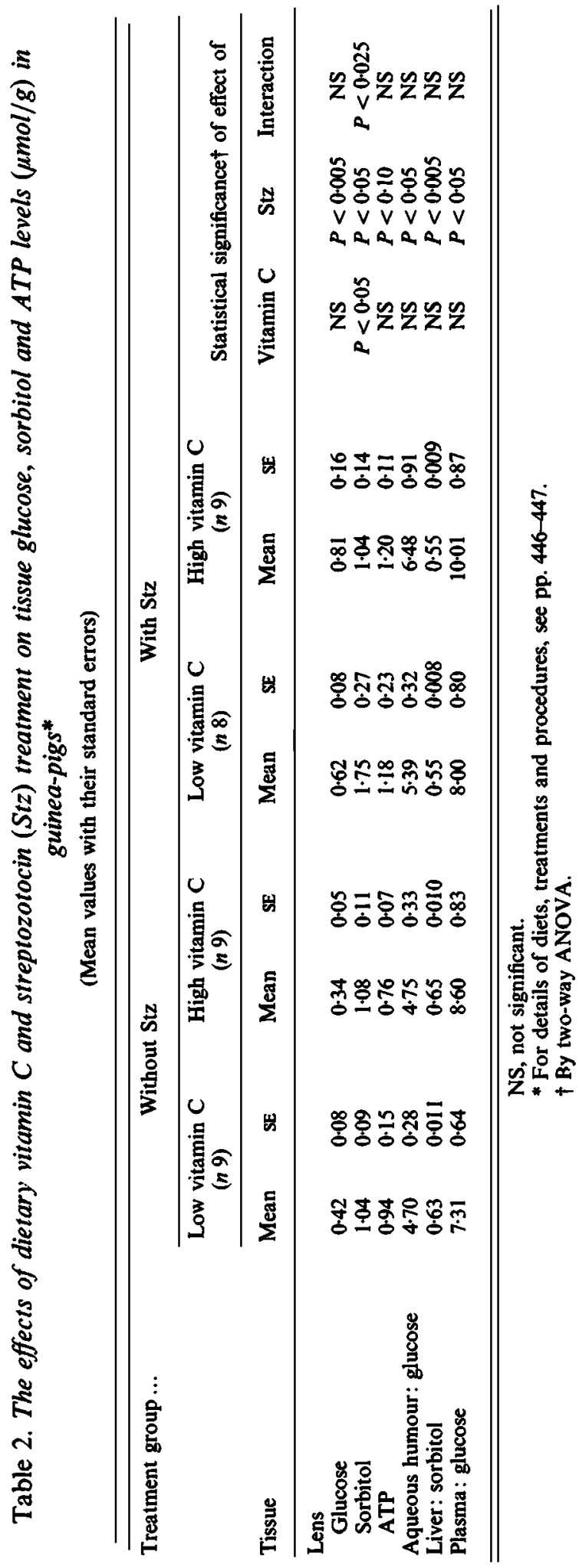




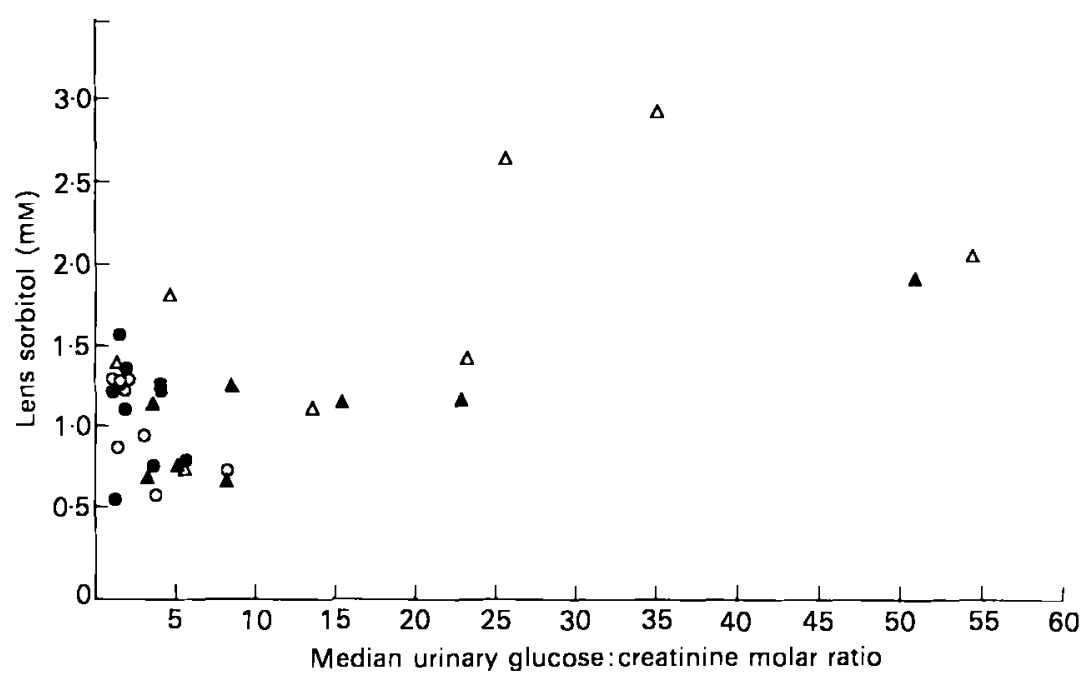

Fig. 4. Lens sorbitol concentrations $v$. median urinary glucose : creatinine molar ratios for each guinea-pig given diets containing high $(5 \mathrm{~g} / \mathrm{kg})$ or low $(0.1 \mathrm{~g} / \mathrm{kg})$ vitamin C levels with or without streptozotocin (Stz) treatment. (O), Without Stz, low vitamin C (n 9); (O), without Stz, high vitamin C $(n 9)$; $(\triangle)$, with Stz, low vitamin C $(n 8)$; $(\Delta)$, with Stz, high vitamin C $(n 9)$. After logarithmic transformation of the displayed values: $r 0.40,34 \mathrm{~d}$; $P<0.02$. For details of diets, treatments and procedures, see pp. $446-447$.

unaffected by either vitamin C or Stz, whereas a previous study (Blondin et al. 1986) found increased endopeptidase activity at low vitamin $\mathrm{C}$ intakes.

The results of urinary glucose excretion following oral glucose loading clearly demonstrated the characteristic diabetogenic effect of Stz in the present study. We are in agreement with Schlosser et al. (1987) on the fact that Stz-treated guinea-pigs seem to exhibit much greater changes in urinary glucose excretion than in blood glucose levels. The fact that only about half the animals responded as expected after two successive doses of Stz (i.e. by reduced weight gain and increased urinary excretion of glucose following a glucose load) is probably due to the lower sensitivity of guinea-pigs to this diabetogenic agent compared with other rodents (Brodsky \& Logothetopoulos, 1969; Wehner \& Majorek, 1975; Schlosser et al. 1984; Gorray et al. 1986). The effect of Stz on glucose excretion gradually waned during the study, which is in accord with previous observations (Wehner \& Majorek, 1975; Gorray et al. 1986). It will be of considerable interest, in future studies, to investigate the time-course of tissue biochemical changes; however, preliminary observations suggest that a prolonged post-dose interval may be essential to produce tissue glucose changes in guinea-pigs.

The results in Figs 2 and 4 indicate that those animals (in the + Stz groups) that consistently had the highest urinary glucose levels following the test dose frequently had low weight gains and a large change in their lens sorbitol levels, suggesting that the effect on lens sorbitol may be related to the diabetogenic effect of the drug. Although the effect of Stz on lens sorbitol at low vitamin C intakes was small, and perhaps not physiologically significant, the observations that a relatively small increase in plasma, aqueous humour and lens glucose levels is associated with a significant effect on sorbitol levels and is modulated by vitamin $C$ intake is of potential interest. The positive correlation of lens ATP levels with urinary glucose in the $+\mathrm{Stz}$ animals may result from the increased sugar levels in the diabetic lens. The absence of a significant Stz effect on lens ATP in Table 2 may be attributable to the Stz 'non-responders' in the Stz-treated groups. In contrast, the 


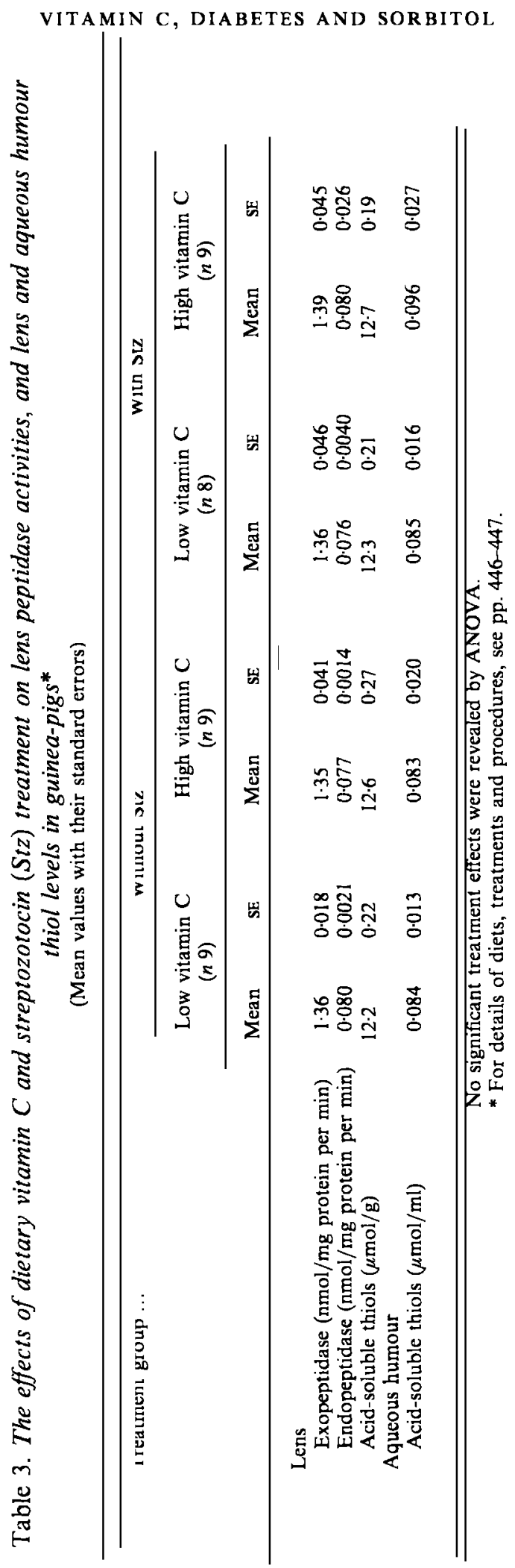


paradoxical reduction in liver sorbitol levels in the + Stz groups was unrelated to the urinary glucose index and may, therefore, have arisen from a disturbance in another unrelated pathway.

The relationships between diabetes, sorbitol accumulation, activities of aldose reductase (EC 1.1.1.21) and sorbitol dehydrogenase, and free-radical-initiated oxidative damage, are only partly understood. In diabetic lenses, aldose reductase activity is increased and that of polyol dehydrogenase (EC 1.1.1.14) is decreased (Varma \& Kinoshita, 1974). Varma (1980), and Kador \& Kinoshita (1984) favour an osmotic theory of diabetic cataractogenesis. However, other evidence (summarized by Harding \& Crabbe, 1984; Barnett et al. 1986; Srivastava \& Ansari, 1988; Simonelli et al. 1989; Malone et al. 1990) and particularly the ameliorative effect of vitamin E (Creighton \& Trevithick, 1979; Ross et al. 1982) point towards additional damage by oxidative processes in the diabetic state. Stz enhances superoxide radical formation in pancreatic $\beta$-cells (Nukatsuka et al. 1988), and Stz-induced diabetes in rats is accompanied by an increase in serum and erythrocyte lipid peroxide levels (Higuchi, 1982; Jain et al. 1990).

Vitamin $\mathrm{C}$ can exhibit either antioxidative or pro-oxidative effects in different models and environments. At high concentrations of the vitamin, in the presence of relatively low concentrations of free or 'activated ' metal ions such as ferrous iron or copper (characteristic of most situations in vivo), the antioxidative properties usually predominate, and ascorbic acid is a free radical chain-terminator (Thurnham, 1988).

Ascorbic acid is actively transported into the lens epithelium (DiMattio, 1989) and high circulating levels of ascorbate may potentiate the tissue utilization of glucose (Von Losert et al. 1980). In granulation tissue from diabetic rats, ascorbic acid prevented collagen abnormalities associated with decreased prolyl hydroxylase $(E C$ 1.14.11.2) activity (McLennan et al. 1988). Vinson et al. (1986) found that galactose-induced cataractogenesis in rats could be countered by ascorbic acid in vivo, and Vinson et al. (1989) showed that ascorbic acid supplementation reduced the accumulation of sorbitol in human erythrocytes in vivo, especially in diabetics. Very recently, Linklater et al. (1990) have reported that vitamin $C$ supplements can reduce the leakage of lens proteins into the aqueous and vitreous humour of Stz-diabetic rats, and Devamanoharan et al. (1991) have reported that the development of cataracts in rat pups exposed to selenite can also be reduced by vitamin $\mathrm{C}$ supplements. Thus a number of recent studies seem to support the hypothesis that enhanced levels of vitamin $\mathrm{C}$ in the lens can exert antioxidant protective activity against cataractogenic insults, including those associated with diabetes.

There is growing interest in the possibility that micronutrients in the diet may affect cataractogenesis in man (Jacques et al. 1988a,b; Gerster, 1989; Taylor 1989). The results from the present pilot study appear to support the hypothesis that the 'protective' functions of vitamin $C$ in vivo take precedence over its 'deleterious' effects as a prooxidant. Clearly further studies are needed to elucidate the mechanism of action of vitamin $\mathrm{C}$ in combating sorbitol accumulation in key tissues, and to relate this to the risk of cataractogenesis.

The authors are indebted to Dr T. J. Cole for his statistical advice.

\section{REFERENCES}

Barnett, P. A., Gonzalez, R. G., Chylack, L. T. \& Cheng, H.-M. (1986). The effect of oxidation on sorbitol kinetics. Diabetes 35, 426-432.

Bates, C. J. \& Cowen, T. D. (1988). Effects of age and dietary vitamin C on the contents of ascorbic acid and acidsoluble thiol in lens and aqueous humour of guinea-pigs. Experimental Eye Research 46, 937-945.

Bensch, K. G., Fleming, J. E. \& Lohmann, W. (1985). The rôle of ascorbic acid in senile cataract. Proceedings of the National Academy of Sciences, USA 82, 7193-7196. 
Bergmeyer, H. U. (1974). D-Sorbitol. In Methods of Enzymatic Analysis, vol. 3, pp. 1323-1332 [H. U. Bergmeyer, editor]. New York: Academic Press.

Blondin, J., Baragi, V., Schwartz, E. R., Sadowski, J. A. \& Taylor, A. (1986). Delay of UV-induced eye lens protein damage in guinea-pigs by dietary ascorbate. Journal of Free Radicals in Biology and Medicine 2 , $275-281$

Bron, A. J. \& Brown, N. A. P. (1986). Perinuclear lens retrodots: a rôle for ascorbate in cataractogenesis. British Journal of Ophthalmology 71, 8695.

Brosky, G. \& Logothetopoulos, J. (1989). Streptozotocin diabetes in the mouse and guinea-pig. Diabetes 18, 606-611.

Cox, B. D., Whichelow, M. J., Butterfeld, W. J. H. \& Nicholas, P. (1974). Peripheral vitamin C metabolism in diabetics and non-diabetics: effect of intra-arterial insulin. Clinical Science and Molecular Medicine 47, 63-72.

Creighton, M. O. \& Trevithick, J. R. (1979). Cortical cataract formation prevented by vitamin E and glutathione. Experimental Eye Research 29, 689-693.

Devamanoharan, P. S., Henein, M., Morris, S., Ramachandran, S., Richards, R. D. \& Varma, S. D. (1991). Prevention of selenite cataract by vitamin C. Experimental Eye Research 52, 563-568.

DiMattio, J. (1989). Active transport of ascorbic acid into lens epithelium of the rat. Experimental Eye Research 49, 878-885.

Elliott, K. R. F. \& Pogson, C. I. (1977). The effects of starvation and experimental diabetes on phosphoenolpyruvate carboxykinase of the guinea-pig. Biochemical Journal 164, 357-361.

Fukui, H. N., Epstein, D. L. \& Kinoshita, J. H. (1973). Ascorbic acid effects on lens ${ }^{86}$ Rubidium transport. Experimental Eye Research 15, 249-253.

Gerster, H. (1989). Antioxidant vitamins in cataract prevention. Zeitschrift für Ernährungswissenschaften 28, $56-75$.

Giblin, F. J., McCready, J. P., Kodama, T. \& Reddy, V. N. (1984). A direct correlation between the levels of ascorbic acid and $\mathrm{H}_{2} \mathrm{O}_{2}$ in aqueous humour. Experimental Eye Research 38, 87-93.

Ginter, E., Zdichynec, B., Holzerova, O., Ticha, E., Kobza, R., Koziakova, M., Cerna, O., Ozdin, L., Hruba, F., Novakova, V., Sasko, E. \& Gaher, M. (1978). Hypocholesterolemic effect of ascorbic acid in maturity-onset diabetes mellitus. International Journal for Vitamin and Nutrition Research 48, 368-373.

Gorray, K. C., Baskin, D., Brodsky, J. \& Fujimoto, W. Y. (1986). Responses of pancreatic B cells to alloxan and streptozotocin in the guinea-pig. Pancreas $1,130-138$.

Greenfield, H., Briggs, G. M., Watson, R. H.J. \& Yudkin, J. (1969). An improved diet for carbohydrate preference studies with rats: some criticisms of experimental diets. Proceedings of the Nutrition Society 28, 43A.

Harding, J. J. \& Crabbe, M. J. C. (1984). The lens: development, proteins, metabolism and cataract. In The Eye, 3rd ed., vol. Ib, pp. 207-492 [H. Davson, editor]. New York: Academic Press.

Higuchi, Y. (1982). Lipid peroxides and $\alpha$-tocopherol in rat streptozotocin-induced diabetes mellitus. Acta Medica, Okayama 36, 165-175.

Jacques, P. F., Chylack, L. T., McGandy, R. B. \& Hartz, S. C. (1988a). Antioxidant status in persons with and without senile cataract. Archives of Ophthalmology 106, 337-340.

Jacques, P. F., Hartz, S. C., Chylack, L. T., McGandy, R. B. \& Sadowsky, J. A. (1988 b). Nutritional status in persons with and without senile cataract: blood vitamin and mineral levels. American Journal of Clinical Nutrition 48, 152-158.

Jain, S. K., Levine, S. N., Duett, J. \& Hollier, B. (1990). Elevated lipid peroxidation levels in red blood cells of streptozotocin diabetic rats. Metabolism 39, 971-975.

Kador, P. F. \& Kinoshita, J. H. (1984). Diabetic and galactosaemic cataracts. In Human Cataract Formation, pp. 110-131, London: Pitman. Ciba Foundation Symposium no. 106.

Klein, R., Engerman, R. L. \& Ernest, J. T. (1980). Fluorophotometry. II. Streptozotocin-treated guinea-pigs. Archives of Ophthalmology 98, 2233-2234.

Kosegarten, D. C. \& Maher, T. J. (1978). Use of guinea-pigs as a model to study galactose-induced cataract formation. Journal of Pharmaceutical Science 67, 1478-1479.

Koskela, T. K., Reiss, G. R., Brubaker, R. F. \& Ellefson, R. D. (1989). Is the high concentration of ascorbic acid in the eye an adaptation to intense solar irradiation? Investigative Ophthalmology and Visual Science 30, $2265-2267$.

Linklater, H. A., Dzialoszynski, T., McLeod, H. L., Sanford, S. E. \& Trevithick, J. R. (1990). Modelling cortical cataractogenesis. XI. Vitamin $\mathrm{C}$ reduces $\gamma$-crystallin leakage from lenses in diabetic rats. Experimental Eye Research 51, 24I-247.

McLennan, S., Yue, D. K., Fisher, E., Capogreco, C., Heffernan, S., Ross, G. R. \& Turtle, J. R. (1988). Deficiency of ascorbic acid in experimental diabetes. Relationship with collagen and polyol pathway abnormalities. Diabetes 37, 359-361

Malone, J. I., Lowitt, S. \& Cook, W. R. (1990). Nonosmotic diabetic cataracts. Pediatric Research 27, $293-296$.

Nishigori, H., Hayashi, R., Jung, W., Lee, K. M. \& Iwatsuru, M. (1985). Preventive effect of ascorbic acid against glucocorticoid-induced cataract formation of developing chick embryos. Experimental Eye Research 40, 445451 .

Nukatsuka, M., Sakurai, H., Yoshimura, Y., Nishida, M. \& Kawada, J. (1988). Ehhancement by streptozotocin of $\mathrm{O}_{2}$-radical generation by the xanthine oxidase system of pancreatic $\beta$-cells. FEBS Letters 239, $295-298$. 
Ortwerth, B. J., Feather, M. S. \& Oleson, P. R. (1988). The precipitation and cross-linking of lens crystallins by ascorbic acid. Experimental Eye Research 47, 155-168.

Pirie, A. (1965). Glutathione peroxidase in lens and a source of hydrogen peroxide in aqueous humour. Biochemical Journal 96, 244-353.

Riley, M. V., Schwartz, C. A. \& Peters, M. I. (1986). Interactions of ascorbic acid and $\mathrm{H}_{2} \mathrm{O}_{2}$. Implications for in vitro studies of lens and cornea. Current Eye Research 5, 207--216.

Rosenbaum, J. T., Howes, E. L \& English, D. (1985). Ascorbate in aqueous humour protects against myeloperoxidase-induced oxidation. American Journal of Pathology 120, 244-247.

Ross, W. M., Creighton, M. O., Stewart-DeHaan, P. J., Sanwal, M., Hirst, M. \& Trevithick, J. R. (1982). Modelling cortical cataractogenesis. 3. In vivo effects of vitamin E on cataractogenesis in diabetic rats. Canadian Journal of Ophthalmology 17,61-66.

Russell, P., Garland, D., Zigler, J. S., Meakin, S. O., Tsui, L. C. \& Breitman, H. L. (1987). Ageing effects of vitamin $C$ on a human lens protein produced in vitro. FASEB Journal 1, 32-35.

Schlosser, M. J., Kapeghian, J. C. \& Verlangieri, A. J. (1984). Effects of streptozotocin in the male guinea-pig: a potential animal model for studying diabetes. Life Sciences 35, 649 655

Schlosser, M. J., Kapeghian, J. C. \& Verlangieri, A. J. (1987). Selected physical and biochemical parameters in the streptozotocin-treated guinea-pig: insights into the diabetic guinea-pig model. Life Sciences 41, 1345-1353.

Simonelli, F., Nesti, A., Pensa, M., Romano, L., Savastano, S., Rinaldi, E. \& Auricchio, G. (1989). Lipid peroxidation and human cataractogenesis in diabetes and severe myopia. Experimental Eye Research 49, $181-187$

Som, S., Basu, D., Mukherjee, S., Deb, P., Choudhury, P. R., Mukherjee, S., Chatterjee, S. N. \& Chatterjee, I. B. (1981). Ascorbic acid metabolism in diabetes mellitus. Metabolism 30, 572-577.

Srivastava, S. K. \& Ansari, N. H. (1988). Prevention of sugar-induced cataractogenesis in rats by butylated hydroxytoluene. Diabetes 37, $1505-1508$.

Stankova, L., Riddle, M., Larned, J., Burry, K., Menashe, D., Har1, J. \& Bigley, R. (1984). Plasma ascorbate concentrations and blood cell dehydroascorbate transport in patients with diabetes mellitus. Metabolism 33, 347-353.

Taylor, A. (1989). Associations between nutrition and cataract. Nutrition Reviews 47, 225-234.

Taylor, A., Jahngen, J. H., Blondin, J. \& Jahngen, E. G. E. (1987). Ascorbic acid delays ultraviolet-induced, agerelated damage to lens protease and the effect of maturation and aging on the function of the ubiquitin-lens protein conjugating apparatus. In Proteases in Biological Control and Biotechnology, pp. 283-293. New York: Alan R. Liss.

Thurnham, D. I. (1988). Vitamin C (ascorbic acid) : antioxidant functions of vitamin $\mathrm{C}$ in disease in man and animals. In Comparative Nutrition, pp. 91-103 [K. Blaxter and I. Macdonald, editors]. London: John Libbey.

Trevithick, J. R., Chaudun, E., Muel, A. S., Courtois, Y. \& Counis, M. F. (1987). Effect of X-irradiation and vitamin C on DNA degradation and endogenous DNase in embryonic chick lens cells. Current Eye Research 6. $1275-1281$.

Varma, S. D. (1980). Aldose reductase and the etiology of diabetic cataracts. Current Topic's in Eye Research 3, $91-155$.

Varma, S. D. (1985). Ascorbic acid and the eye, with special reference to the lens. Annals of the New York Academy of Sciences 498, 280-305.

Varma, S. D. \& Kinoshita, J. H. (1974). Sorbitol pathway in diabetic and galactosemic rat lens. Biochimica et Biophysica Acta 338, 632-640.

Varma, S. D. \& Richards, R. D. (1988). Ascorbic acid and the eye lens. Ophthalmic Research 20, 164-173.

Vinson, J. A., Possanza, C. J. \& Drack, A. V. (1986). The effect of ascorbic acid on galactose-induced cataracts. Nutrition Reports International 33, 665-668.

Vinson, J. A., Staretz, M. E., Bose, P., Kassm, H. M. \& Basalyga, B. S. (1989). In vitro and in vivo reduction of erythrocyte sorbitol by ascorbic acid. Diabetes 38, 1036-1041.

Von Losert, W., Vetter, H. \& Wendt, H. (1980). The influence of vitamin C (ascorbic acid) on glucose tolerance, insulin activity and insulin elimination from the blood. Arzneimittel-Forschung 30, 21-29.

Wehner, H. \& Majorek, B. (1975). Early glomerular changes in streptozotocin diabetes of the guinea-pig. Virchows Archiv A: Pathology, Anatomy and Histology 368, 179-189.

Williams, R. N. \& Paterson, C. A. (1986). A protective role for ascorbic acid during inflammatory episodes in the eye. Experimental Eye Research 42, 211-218.

Yew, M. S. $(1983 a)$. Effect of streptozotocin diabetes on tissue ascorbic acid and dehydroascorbic acid. Hormone and Metabolic Research 15, 158.

Yew, M.S. (1983b). Ascorbic acid supplementation and induction of diabetes in rats. Nutrition Reports International 27, 297-302.

Zebrowski, E. J. \& Bhatnagar, P. K. (1979). Urinary excretion pattern of ascorbic acid in streptozotocin-diabetic and insulin-treated rats. Pharmacological Research Communications 11, 95-103. 